\title{
IMPLANTAÇÃO DO ENSINO HÍBRIDO EM CURSOS DE GRADUAÇÃO NAS FACULDADES SÃO JOSÉ: RELATO DE EXPERIÊNCIAS
}

RIO DE JANEIRO/RJ AGOSTO/2018

\author{
Rita de Cássia Borges de Magalhães Amaral - FSJ - ritaborgesead@gmail.com \\ Adriane Pereira Gouvêa - FSJ - adrianeGouvEA@GMAIL.COM \\ Rosimeri Claudiano da Costa - FSJ - rosic.costa@hotmail.com \\ Saulo Ribeiro de Oliveira Mello - FSJ - saaaaauloribeiro@gmail.com \\ Fernanda Nunes de Souza - FSJ - nandasouzanunes@gmail.com \\ Mônica Muhlbauer - FSJ - momuhlbauer@gmail.com
}

Tipo: Relato de Experiência Inovadora (EI)

Categoria: Métodos e Tecnologias

Setor Educacional: EDUCAÇÃO SUPERIOR

\begin{abstract}
RESUMO
O objetivo desta pesquisa é analisar o processo de implementação do ensino híbrido em uma Instituição de Ensino Superior Privada do Estado do Rio de Janeiro. O estudo de caso avaliou as metodologias e o fazer pedagógico de sete disciplinas curriculares distribuídas em três grandes áreas de conhecimento - Enfermagem, Odontologia e Pedagogia - demonstrando que as novas tecnologias se tornaram importantes ferramentas para o trabalho em sala de aula, seja esse ambiente físico ou virtual, conduzindo para um novo aluno mais participativo, construtor de conhecimento e colaboração.
\end{abstract}

Palavras-chave: EaD- Ensino Híbrido e Implantação 


\section{1- INTRODUÇÃO}

A Sociedade de Informação (SI) foi um fenômeno marcado pelo despertar das tecnologias da informação e comunicação que afetou diretamente as atividades econômicas e sociais globais, tornando possíveis novas formas de acesso e distribuição do conhecimento (CASTELLS, 1999; TAKAHASHI, 2009). Este novo paradigma social tem no intenso fluxo de informações e no conhecimento flexível, fluido e em constante expansão suas maiores características (COUTINHO \& LISBOA, 2011).

A SI e suas tecnologias trouxeram contribuições relevantes para o processo educacional, transformando o modelo tradicional, antes passivo, em aprendizado interativo. Uma era de múltiplas possibilidades de aprendizado se inaugurou, demandando novas metodologias de ensino e, consequentemente novos suportes pedagógicos, transformando o papel do professor e dos estudantes (CHRISTENSEN, STAKER \& HORN, 2013).

Segundo Valente (2014), até os anos 1980 o modelo e-learning estava fundamentalmente baseado no material impresso que era devidamente preparado, enviado ao aprendiz e utilizado de acordo com a sua disponibilidade de tempo e local de estudo. Contudo, sabemos que o ensino à distância se diversificou. E neste sentido, a metodologia híbrida, blended-learning ou b-learning vem ganhando destaque nas pesquisas do campo pedagógico como estratégia positiva que se aproxima de uma posição mais centrada no aluno e mais sensível às suas respectivas necessidades. $O$ conceito é caracterizado pelo uso de uma variedade de métodos de aprendizagem que contribuem para o estímulo da colaboração entre os participantes, permitindo troca de experiências, acelerando o aprendizado individual através da construção coletiva de saberes (CHAVES FILHO, et al, 2006). Os docentes têm um papel fundamental neste processo pois, ao adotar essa metodologia em sua aula presencial, promovem uma aula mais atraente e interativa, desenvolvendo o pensamento crítico dos estudantes, estimulando-os na construção de soluções criativas e na formação de equipes, competências essenciais no mercado de trabalho (TORRES, BORBA et. al.; 2014)

Nosso trabalho visa contribuir para a análise da implementação do ensino híbrido no ensino superior, apresentando os primeiros resultados, perspectivas e desafios das vivências pedagógicas da metodologia híbrida nas Faculdades São José, instituição privada localizada na zona oeste do Estado do Rio de Janeiro. Optamos por realizar um estudo de caso onde selecionamos quatro disciplinas e os seguintes cursos, respectivamente - Disciplina de Oclusão; Fisiologia Humana; Histologia e Embriologia para o curso de Odontologia; e Metodologias Ativas no Processo de Ensino 
Aprendizagem - para as graduações de Educação Física e Pedagogia. Foram analisadas as atividades com aproximadamente 400 alunos.

A relevância desta pesquisa não se dá apenas pelo crescimento do número de matrículas nos cursos de graduação a distância com reconhecida qualidade de ensino no Brasil, fato observado pelas estatísticas do Instituto Nacional de Estudos e Pesquisas Educacionais Anísio Teixeira (INEP/MEC, 2016). Mas, especialmente, pelo processo de democratização que o ensino superior brasileiro apresentou, trazendo para este cenário uma população estudantil de diferentes espectros sociais - possuidores de capitais econômicos e culturais alheios a então tradição universitária, obrigando gestores e professores das instituições de ensino a repensarem em diferentes estratégias de aprendizagem.

\section{2- O CONCEITO E AS CARACTERÍSTICAS DO ENSINO HÍBRIDO.}

Difundido em algumas instituições de educação básica e superior nos Estados Unidos, Canadá e América Latina, o ensino híbrido surgiu como possibilidade metodológica para atender as necessidades dos estudantes, buscando a potencialização de suas capacidades. É notório que os alunos aprendem em diferentes ritmos. Assim, é importante que o professor desenvolva estratégias diferentes, com o objetivo de garantir o aprendizado de todos, não necessariamente ao mesmo tempo. Portanto, um modelo de ensino personalizado focado na individualidade de cada aluno como o ensino híbrido seria capaz de garantir a máxima eficiência na sua aprendizagem (SILVA, 2016).

Envolvendo elementos do modelo de aprendizagem tradicional com os benefícios que as tecnologias digitais de informação oferecem, o blended learning permite ao aluno controlar quando, onde, como e com quem vai estudar através das atividades online. Existe um aspecto formal para diferenciar as situações de aprendizagem que acontecem informalmente, isto é, o conteúdo e as instruções devem ser elaborados especificamente para a disciplina ao invés de usar qualquer material que o aluno acessa na internet. Além disso, a parte presencial deve necessariamente contar com a supervisão do professor, valorizar as interações interpessoais e ser complementar às atividades online, proporcionado um processo de aprendizagem mais eficiente e interessante (VALENTE, 2014).

Para Silva (2016), o ensino híbrido pode ser classificado em dois grandes grupos: inovações sustentadas e inovações disruptivas. Denominamos inovações sustentadas aquelas que buscam a integração entre método tradicional e a metodologia online, não causando grandes rompimentos e sem grandes custos para as instituições de ensino. 0 
tipo de material ou atividades que o aluno realiza on-line e na sala de aula variam de acordo com a proposta a ser implantada, criando diferentes possibilidades para essa abordagem pedagógica. Neste grupo encontramos os modelos de rotação que, por sua vez, podem ser subclassificados em: a - Rotação porEstações; b - Laboratório Rotacional: c - Rotação Individual; d - Sala de Aula Invertida ou Flipped Classroom. Já as inovações disruptivas são aquelas que utilizam o ensino online em modelos que se afastam da sala de aula tradicional. Nesse modelo as instituições de ensino tendem a se distanciar do modelo tradicional, bem como, utilizar a tecnologia como a principal fonte de acesso ao conhecimento (SILVA, 2016). São exemplos de inovações disruptivas os modelos flex, à la carte e virtual enriquecido.

É importante ressaltar que para o sucesso da implantação do ensino híbrido é preciso planejamento e organização de todas as atividades que serão realizadas a distância. É fundamental que a Instituição de Ensino Superior implante um Núcleo de Educação a Distância (NEAD), o qual caberá realizar estudos e pesquisas a respeito da educação a distância e ficará responsável, através de uma equipe multidisciplinar, pela organização de todas atividades relacionadas a EAD (JÚNIOR, 2017).

\section{3- METODOLOGIA}

Para a realização desta pesquisa, optamos por apresentar e discutir os estudos de caso de cada disciplina selecionada: Disciplina de Oclusão; Fisiologia Humana; Histologia e Embriologia; Metodologias Ativas no Processo de Ensino Aprendizagem.

Para as disciplinas de Fisiologia Humana, Histologia e Embriologia foram utilizados questionários online cujo objetivo era avaliar o nível de aprendizagem dos alunos em sala de aula, de acordo com os casos clínicos abordados previamente. Os questionários supracitados poderiam ser acessados durante a aula, através de seus celulares. À medida que respondiam às perguntas, recebiam a informação de acerto ou erro, tendo, dessa forma, sua nota ao final do método. Para a disciplina de Oclusão foram disponibilizados vídeos, aulas em PDF, artigos e livros para cada unidade da disciplina. Já para a disciplina Metodologias Ativas No Processo de Ensino Aprendizagem foram oferecidos textos das unidades com vídeos e fóruns avaliativos obrigatórios na composição da nota final, nos quais os alunos foram orientados a participar. Vale ressaltar que todas as atividades citadas na metodologia desta pesquisa foram hospedadas no Ambiente Virtual de Aprendizagem da instituição - AVA - da instituição. 


\section{4 - APRESENTANDO OS RELATOS DE EXPERIÊNCIAS}

\section{1- O Ensino Híbrido nas disciplinas de Fisiologia Humana, Histologia e Embriologia}

Lidamos atualmente com a geração Millenials (geração $Y$ ) e a sua sucessora geração Z, ou seja, pessoas nascidas em meados da década de 90 e o início dos anos 2000. Jovens que já nasceram na nova era da tecnologia, pós internet, com acesso a smartphones, e-mails, etc. É a primeira geração verdadeiramente globalizada, tendo informação disponível em qualquer lugar e a qualquer momento. Esses jovens sentem como se fossem os controladores das informações.

Para tais alunos, a informação encontra-se na palma das mãos e em tempo real. Dessa forma, as instituições de ensino devem romper a forma tradicional de ensinar, acompanhando as novas tecnologias, entendendo os anseios dessa nova geração. $\mathrm{E}$ cabe a nós professores, dentre tantas funções, conseguirmos captar o interesse do aluno, não só pelo conhecimento, como pela didática abordada. Não nos cabe mais o papel de apenas ensinar, mas de orientá-los e apoiá-los na busca e conexões de informações.

$\mathrm{Na}$ disciplina de Fisiologia Humana, do curso de Odontologia, aplicamos os questionários online para avaliarmos o nível de aprendizagem dos assuntos previamente abordados em sala de aula. Os resultados indicaram que o método foi positivamente recebido pelos graduandos. Os alunos demonstraram grande entusiasmo ao participarem das atividades propostas, uma vez que utilizavam seus próprios smartphones, que já estão presentes nos seus hábitos e estilo de vida. Um dos pontos a serem destacados foi a capacidade que o estudante desenvolveu em identificar os pontos da matéria que precisariam ser reforçados. O debate em sala de aula foi estimulado, bem como o reforço do conteúdo da disciplina.

Para a disciplina de Histologia, seguimos a mesma linha de raciocínio aplicado na Fisiologia Humana, mas optamos também por disponibilizar na plataforma AVA as fotos das lâminas histológicas abordadas no laboratório para facilitar o estudo dos alunos. Os exercícios online para testarem os conhecimentos debatidos em sala de aula também foram aplicados, com resultados semelhantes a disciplina Fisiologia Humana.

Vale destacar que em ambas disciplinas, os alunos estão acessando a plataforma com maior periodicidade e relataram que os questionários aplicados estão os auxiliando de modo significativo em relação ao aprendizado. Os graduandos estão, inclusive, 
solicitando cada vez mais exercícios online.

\section{2.- O Ensino Híbrido na disciplina de Oclusão}

Para a disciplina de Oclusão foram observadas a metodologia do ensino híbrido ou blended-learning em estudantes do terceiro período do curso de graduação em Odontologia no primeiro semestre de 2018. Uma turma do turno da manhã com 54 alunos e outra da tarde com 55 alunos.

Para um melhor aproveitamento da disciplina, optamos por dividí-la em quatro etapas: 1. Conceitos - local sala de aula; 2. Diagnóstico de Disfunção Temporomandibulares; 3. Montagem dos modelos no articulador - local grupo I e II clínica odontológica; 4. Conferência dos contatos obtidos no ASA, na boca utilizando carbono - local grupo I e II clínica odontológica.

$\mathrm{Na}$ primeira etapa, a dos conceitos, os alunos foram informados sobre anatomia, princípios básicos de oclusão, métodos de exame clínico, diagnóstico e metodologia da pesquisa em aulas teóricas e debates sobre temas relacionados em artigos científicos.

As três primeiras aulas foram aulas expositivas sobre os temas anatomia, princípios básicos de oclusão, métodos de exame clínico. Após estas primeiras aulas, foram orientados para realizarem pesquisa sobre os temas discutidos nas aulas em artigos científicos que auxiliaria na participação de uma atividade prática sobre exame clínico e nesse momento questionados e avaliados sobre os temas apresentados nas aulas teóricas através de um teste no AVA (As médias das notas do teste no AVA estão na tabela 1). Estas duas atividades contaram como nota de Avaliação Continuada (AC) somando 2 (dois) pontos na primeira nota do semestre que serão somados à nota da prova. Cada etapa do exame clínico foi devidamente demonstrada com o auxílio de um vídeo confeccionado por monitores e alunos de iniciação científica da disciplina, foram dados 20 minutos para que realizem cada atividade, após este tempo, foram quantificados o grau de dificuldade dos alunos na realização de cada etapa e o número de auxílios solicitados. Houve uma segunda prática de fechamento de diagnóstico na qual os alunos puderam discutir sobre os critérios de diagnósticos para cada grupo.

Foi realizado uma aula antes da prova um teste com dez questões objetivas sobre os temas discutidos até o momento cuja discussão e correção serviu de revisão para a prova. 


\section{3- Formação docente nos cursos de Pedagogia e Educação Física na disciplina de Metodologias Ativas no processo de ensino aprendizagem}

As abordagens pedagógicas baseadas nas metodologias ativas e no ensino híbrido foram aplicadas para estudantes dos cursos de Pedagogia e Educação Física que, a cada unidade, tinham à disposição textos com vídeos e fóruns avaliativos obrigatórios na composição da nota final, nos quais os alunos foram orientados a participar.

A interatividade tanto no ambiente presencial quanto no virtual foi um ponto a ser destacado na disciplina. Ao longo das aulas foram criadas estratégias baseadas no design thinking com a construção de mapas mentais e conceituais de forma individual e coletiva. É do conhecimento de todos participantes que a disciplina seria o resultado de uma avaliação permanente, realizada a cada aula.

Foram aplicados cinco processos avaliativos que serviram para compor a nota da primeira avaliação - TA1, a saber: construção de mapas mentais, estudo dirigido com elaboração de perguntas e respostas sobre o conteúdo das unidades da disciplina, gamificação baseada no item anterior, apresentação de vídeos com proposta de produção textual acerca dos temas e apresentação de seminário.

Foi possível considerar que os resultados da disciplina, foram positivos tanto em relação às notas finais quanto em participação nas aulas. De dez alunos do curso de Educação Física, oito alunos obtiveram notas finais acima de 9,0. Apenas dois alunos não apresentaram resultados positivos, pois desistiram da disciplina. No curso de Pedagogia, dentre o total de setenta e quatro alunos inscritos, foi possível obter a média global de 7,5 nos resultados da disciplina.

Podemos destacar que a frequência em sala bem como a participação dos estudantes foram positivas, mesmo levando em consideração o perfil diferenciado do discente do curso de Educação Física, cuja proposta de aluno ativo já está presente nas características do curso. No curso de Pedagogia, a frequência e participação também foi positiva, uma vez que não foram aplicadas avaliações escritas, tais como provas que não condiziriam com a proposta e ativa, bem como constante de avaliação da disciplina.

Os resultados finais obtidos pela implementação do ensino híbrido concomitantemente com as metodologias ativas baseadas nas novas tecnologias de informação e comunicação, serão finalizados somente após o encerramento do período corrente de 
2018.1. Contudo, já é notório o engajamento dos discentes na proposta da disciplina, bem como a participação colaborativa para uma aprendizagem efetiva e significativa, fatores condizentes com o que se espera do perfil de um aluno de graduação ativo, atuante e produtor de conhecimento reflexivo e científico.

\section{5- CONSIDERAÇÕES FINAIS}

Conforme a proposta apresentada no presente relato, é possível considerar que a cada dia o espaço acadêmico demanda novos desafios, compostos por inovações, novas tecnologias, mediação, colaboração e interatividade.

A sala de aula ganha diferentes especificidades e possibilidades, cuja proposta de aprendizagem efetiva traz um olhar significativo e transdisciplinar. Sabemos da importância do trabalho docente como ponto balizador do fomento à produção de conhecimento, bem como, meio condutor da mediação do processo ensino aprendizagem.

As experiências aqui relatadas são uma forte referência para que o trabalho docente vá para além da sala de aula tradicional e promove uma reflexão sobre o quão necessário se faz empreender o ensino híbrido.

\section{Referências Bibliográficas}

CASTELLS, Manuel. (1999). A Era da Informação: economia, sociedade e cultura, vol. 3. São Paulo: Paz e terra.

CHAVES FILHO, Hélio. Et al. Educação a distância em organizações públicas; mesaredonda de pesquisa-ação. Brasília: ENAP, 2006. 200 p. Disponível em: <www.enap.gov.br/index.php?option=com_docman\&task=doc_download\&gid=2312> . Acesso em março de 2018.

COUTINHO, Clara; LISBÔA, Eliana. Sociedade da informação, do conhecimento e da aprendizagem: desafios para educação no século XXI. Revista de Educação, v. 18, n. 1 , p. 5-22, 2011. Disponível em <http://revista.educ.fc.ul. pt/arquivo/vol_XVIII_1/artigo1.pdf>. Acesso em março de 2018. 
CHRISTENSEN, Clayton; HORN, Michael B.; STAKER, Heather. Ensino híbrido: uma inovação disruptiva? Uma introdução à teoria dos híbridos. In: http://porvir.org/wpcontent/uploads/2014/08/PT_Is-K-12-blended-learning-disruptiveFinal.pdf. Acesso em março de 2018.

JúNIOR, Eli Cândido. Gestão de EAD no Ensino Híbrido. Uma pesquisa sobre a organização e utilização da sala de aula invertida. 23ํㅡㄹ CIAED. Setembro 2017. In: www.abed.org.br/congresso2017/trabalhos/pdf/221.pdf. Acesso março de 2018

SCHIEHL, Edson Pedro; GASPARINI, Isabela. Contribuições do Google Sala de Aula para o Ensino Híbrido. Nova Tecnologias da Educação. CINTED-UFRGS V.14. no 2. dezembro. 2016. In: seer.ufrgs.br/index.php/renote/article/view/70684. Acesso março de 2018

SILVA, Jorge Everaldo Pittan da. Ensino Híbrido: Possíveis contribuições para a qualificação do Ensino de História no Ensino Médio. Trabalho final apresentado ao Programa de Mestrado Profissional em Ensino de História em Rede Nacional na Universidade Federal de Santa Maria. UFSM. 2016.

TAKAHASHI, Tadao (Org) (2000). Sociedade da informação no Brasil: Livro Verde. Brasília: Ministério da Ciência e Tecnologia. Disponível em: http://www.instinformatica.pt/ servicos/informacao-e-documentacao/biblioteca-digital/gestaoeorganizacao/BRASIL_livroverdeSI.pdf. Acesso em março de 2018.

TORRES, Kelli; BORBA, Erika et. al. Implantação da metodologia hibrida (blended learning) de educação numa instituição de ensino privada. XI Congresso Brasileiro de Educação a Distância. Florianópolis. 2014. Acesso em março de 2018.

VALENTE, José Armando. Blended learning e as mudanças no ensino superior: a proposta da sala de aula invertida. Educ. rev. [online]. 2014, n.spe4, pp.79-97. Acesso em março de 2018. 